\section{Đô thị đại học -mô hình mới trong giáo dục đại học}

\section{Huỳnh Thị Hồng Thúy ${ }^{1}$}

${ }^{1}$ Khoa Kiến Trúc, Trường ĐH Xây dựng Miền Tây

TỪ KHOÁ TÓM TẮT

Đô thị đại học

KEYWORDS

Urban University
Đô thị đại học là một mô hình phát triển cao của nền giáo dục tiên tiến tại một số quốc gia trên thế giới. Nó đảm nhận chức năng giáo dục đồng thời đáp ứng các nhu cầu cơ bản của cộng đồng. Các trường đại học hiện nay có xu hướng ngày càng mở rộng về quy mô, hoặc sáp nhập giữa các trường tạo thành những cụm đại học có diện tích tương đương một đô thị. Ở Việt Nam, mô hình đô thị đại học cũng bắt đầu hình thành như Làng đại học Thủ Đức, đô thị đại học Võ Trường Toản... Bằng cách khảo sát, so sánh một vài đô thị đại học trên thế giới như Đại học Harvard, Đại học Oxford, Đại học Tsukuba... hay các dự án đô thị đại học trong nước như Đại học quốc gia Hà Nội, Đại học Đà Nẵng, Đại học quốc gia thành phố Hồ Chí Minh...Bài viết trình bày về quá trình hình thành cũng như định hướng phát triển của một số các đô thị đại học hiện nay.

\section{Tồng quan}

"Đô thị đại học" có thể được hiểu là một môi trường giáo dục trong đó hội đủ các điều kiện về hạ tầng kỹ thuật, hạ tầng xã hội. Hiện nay, có nhiều khái niệm tương tự "Đô thị đại học" được sử dụng như: "Thành phố khoa học", "Thành phố sinh viên", "Khu đại học", "Cộng đồng đại học”... Đô thị đại học có khuôn viên nằm trong một khu vực đô thị với sự hiện diện của các tổ chức giáo dục có ảnh hưởng lớn đến đời sống kinh tế và xã hội của đô thị đó. Nơi đây cung cấp đa dạng các chương trình đào tạo, các loại hình tiếp cận các vấn đề trên nhiều lĩnh vực khoa học; sử dụng kinh nghiệm thực tế trong môi trường đô thị để nâng cao trình độ học vấn của người học. Một đô thị đại học thường có đầy đủ các công trình hạ tầng kỹ thuật như: đường sá, cầu cống, các trạm cấp điện cấp nước...; các công trình hạ tầng xã hội như: bệnh viện, công viên, nhà thi đấu...; các công trình phục vụ mục đích nghiên cứu giáo dục như: cụm giảng đường hiện đại, khu nghiên cứu khoa học, thư viện, ký túc xá sinh viên và khu nhà ở cho giảng viên. Tất cả đều xoay quanh hạt nhân chính là các trường đại học nhằm tạo môi trường tốt nhất cho sự phát triển giáo dục đại học cả về quy mô lẫn chất lượng.
Mục tiêu của đô thị đại học là cung cấp các chương trình đại học, sau đại học; giúp sinh viên sống trong cộng đồng đô thị có thể tiếp cận được không chỉ có mục tiêu đào tạo, mà còn đẩy mạnh nghiên cứu; thúc đẩy các sáng kiến của sinh viên, công nhận các con đường phát triển chuyên nghiệp của sinh viên.

\section{Một số đô thị đại học trên thế giới}

Vào thời cổ đại, mô hình đô thị đại học đã dần xuất hiện với các cơ sở học tập bậc cao được thiết lập ở nhiều nền văn hóa, cung cấp môi trường cho các hoạt động học tập và nghiên cứu. Một số địa điểm có thể kể đến như học viện Platon (Athens - Hy Lạp) hay viện nghiên cứu Mouseio (Ai Cập) nổi tiếng là những trung tâm nghệ thuật, học thuật và triết học với nhiều phát kiến khoa học đã ra đời tại đây.

Cáchthứchình thành đô thị đại học ở các nước chủ yếu chia làm hai loại:

- Thứ nhất: đô thị đại học được hình thành tự nhiên như đại học tại Boston, Harvard và MIT (Mỹ), Oxford và Cambridge (Anh)... Những khu vực này đều có quá trình hình thành phát triển tự nhiên qua 
hàng trăm năm, lịch sử của thành phố thường đan xen với lịch sử của trường đại học. Nền kinh tế của thành phố liên quan chặt chẽ với hoạt động của trường đại học và được hỗ trợ bởi toàn bộ cấu trúc trường đại học.

- Thứ hai: đô thị đại học được xây dựng với quy mô tương đối hoàn chỉnh ngay từ đầu như đại học Tsukuba (Nhật Bản), đô thị đại học thành phố Côn Minh, Vân Nam (Trung Quốc)...

\section{1. Đai hoc Harvard (Mỹ)}

TrườngHarvard được thành lập năm 1636, lúc đầu chỉ có một giáo viên và 9 học sinh. Đến nay Harvard có khoảng 6794 nhân viên, 1334 giáo viên, 20343 sinh viên.

Harvard ban đầu là một khu vực trường nhỏ, với những ngôi nhà độc lập. Mỗi ngôi nhà đều có một khuôn viên riêng với những giảng đường, ký túc xá và khu văn phòng. Do được phát triển dần theo thời gian nên mỗi khu vực của trường đều hoàn thiện dần các công năng như giảng đường, phòng thí nghiệm, ký túc xá. Hiện nay, tại đây tập trung xây dựng rất nhiều những trung tâm nghiên cứu, thí nghiệm chuyên ngành và các công ty, đơn vị kỹ thuật.

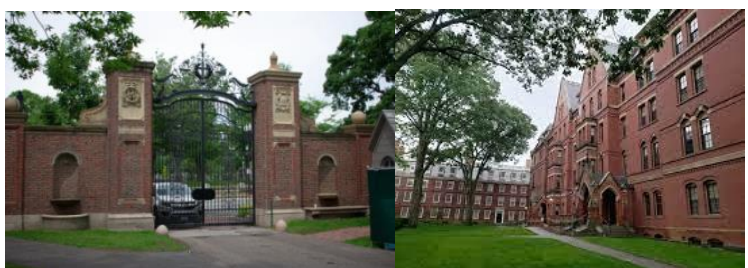

Hình 1. Cổng Johntston và khu giảng đường của đại học Harvard [1].

Thông thường, người ta lựa chọn cổng Johntston để tiếp cận ngôi trường. Cổng được thiết kế theo phong cách Phục hưng với những họa tiết trang trí đặc sắc. Bên cạnh đó chúng ta cũng có thể dễ dàng nhận diện được những giảng đường với màu nâu đỏ đặc trưng của ngôi trường trăm tuổi.

Hệ thống thư viện của đại học Harvard đứng đầu trong hệ thống thư viện nước Mỹ với hơn 80 thư viện, chứa đến 18 triệu tài liệu.

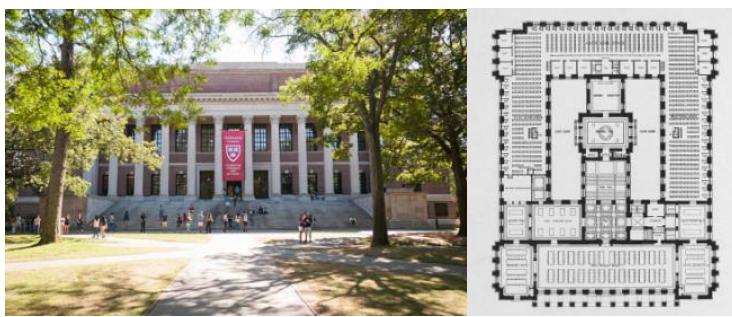

Hình 2. Thư viện Widerner của Harvard [2].

Thư viện Widerner -trái tim của đại học Harvard có mặt bằng hình chữ nhật với hàng cột lớn phía trước tạo nên sự trang trọng cho công trình.
Căn tin của trường cũng thường được nhắc đến với những xuất ăn phong phú. Điểm nhấn của nhà ăn là tông màu nâu gỗ ấm cúng, kết cấu mái vòm và trang trí bằng những chiếc đèn chùm cỡ lớn.

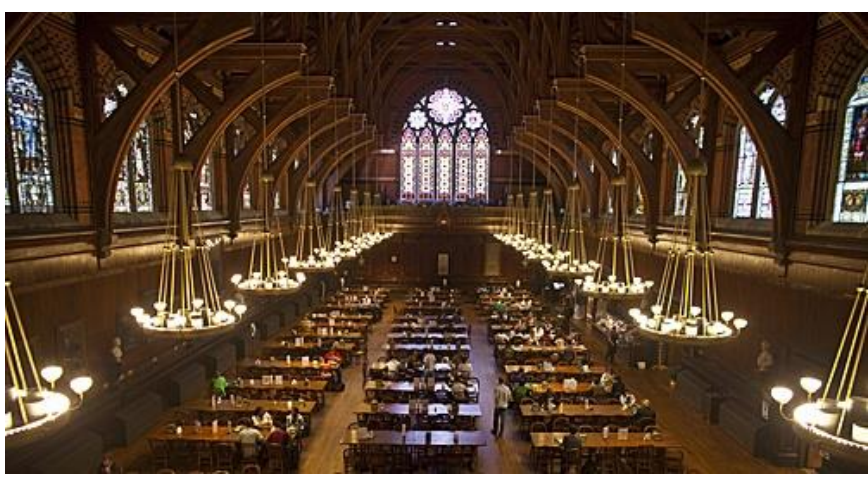

Hình 3. Một khu vực nhà ăn của đại học Harvard [3] .

\section{2. Đại học Boston (Mỹ)}

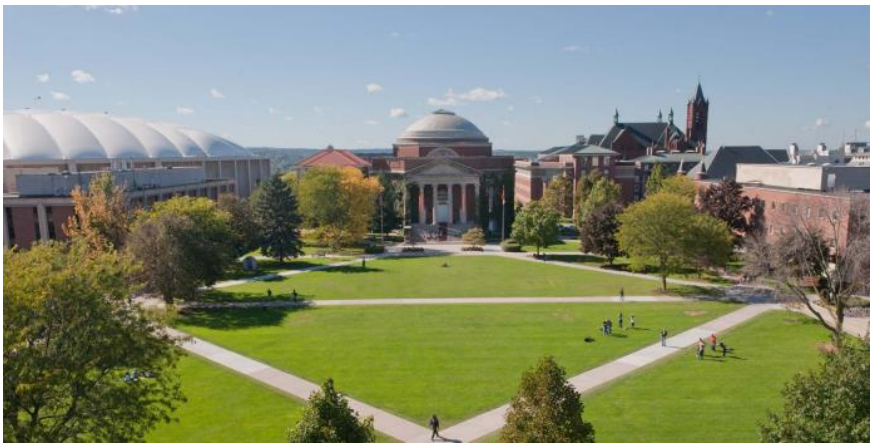

Hình 4. Đại học Boston [4].

Đại học Boston được thành lập năm 1839, với tiền thân là Viện Newbury Biblical tại Newbury, Vermont. Nằm ở trung tâm của Boston lịch sử, với quy mô khuôn viên là 134 mẫu Anh, đại học Boston là một trường đại học giảng dạy và nghiên cứu với hơn 15 trường đại học, cao đẳng, hơn 300 chuyên ngành và hơn 650 khóa học toàn cầu.

Trường hiện có 23 thư viện phân bố đều tại các khuôn viên của trường, hơn 2300 phòng thí nghiệm, hơn 70 tổ chức về nghệ thuật và trình diễn. Cùng với đó trường còn thành lập hơn 100 câu lạc bộ sinh viên về các lĩnh vực thể thao, đời sống, học tập... cho các sinh viên có cùng sở thích tham gia. Các dịch vụ trong khuôn viên trường và các dịch vụ hỗ trợ sinh viên cũng hoạt động liên tục, đảm bảo điều kiện tốt nhất cho việc học tập và sinh sống của sinh viên.

\section{3. Đại hoc Oxford và Cambridge (Anh)}

- Đại học Oxford: 
Đại học Oxford có hơn 40 trường thành viên hợp lại, không có tường bao ngăn cách với thành phố, không có cổng trường. các trường này đều tự điều hành, nhưng có một bộ phận quản lí chung đứng đầu. Các khoa, viện chuyên ngành được phân bố khắp đô thị. Các tiện nghi giáo dục đáp ứng đầy đủ cho mọi cấp học. Phần lớn các trường thành viên của đại học Oxford có lịch sử lâu đời hơn 800 năm với phong cách kiến trúc thời Trung cổ tạo cảm giác uy nghi, bề thế.

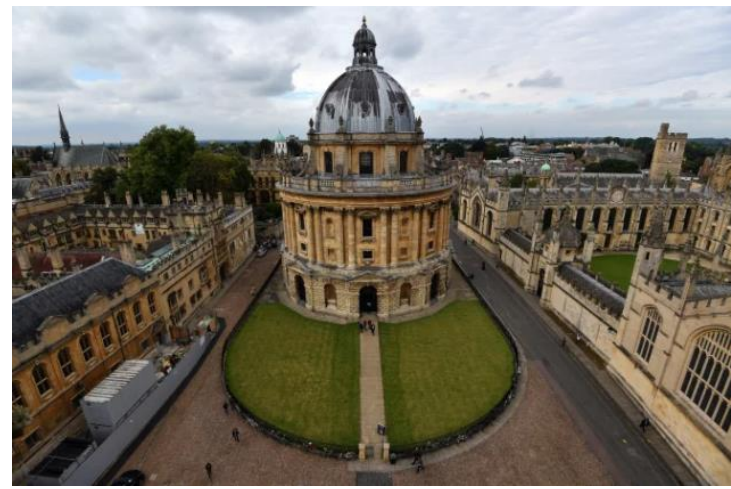

Hình 5.Đại học Oxford [5].

Đại học Oxford có 102 thư viện, trong đó có 30 thư viện thuộc chuỗi thư viện Bodleian - thư viện nghiên cứu trung tâm của viện đại học - nơi có mọi bản sao của tất cả các cuốn sách xuất bản ở Anh.
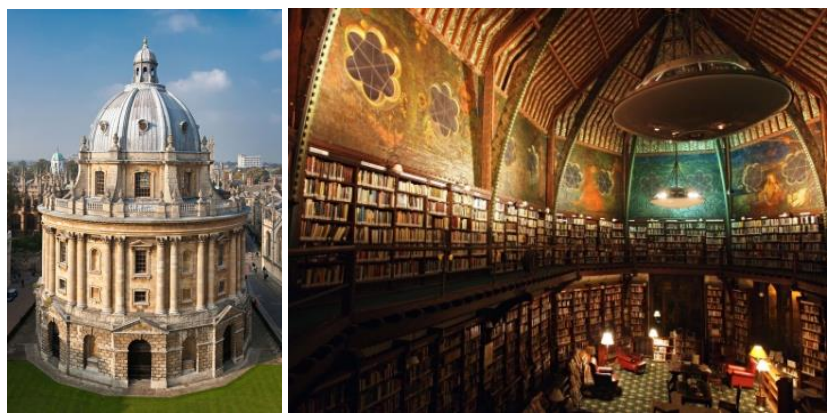

Hình 6. Phòng đọc Radcliffe (thư viện Bodleian) được xây dựng vào năm 1749 với kiến trúc mái vòm rất ấn tượng [6].

Giảng đường của đại học Blavatnik (thuộc Đại học Oxford) được thiết kế cong để tạo điều kiện tương tác tốt hơn giữa các sinh viên cũng như với giảng viên, được trang bị các phương tiện nghe nhìn hiện đại. Không gian giảng dạy linh hoạt, có thể được sử dụng như một phòng lớn duy nhất cho các bài giảng và hội nghị với sức chứa lên đến 200 người hoặc được chia thành bốn không gian riêng biệt cho các cuộc hội thảo, thảo luận nhóm và họp nhỏ hơn.

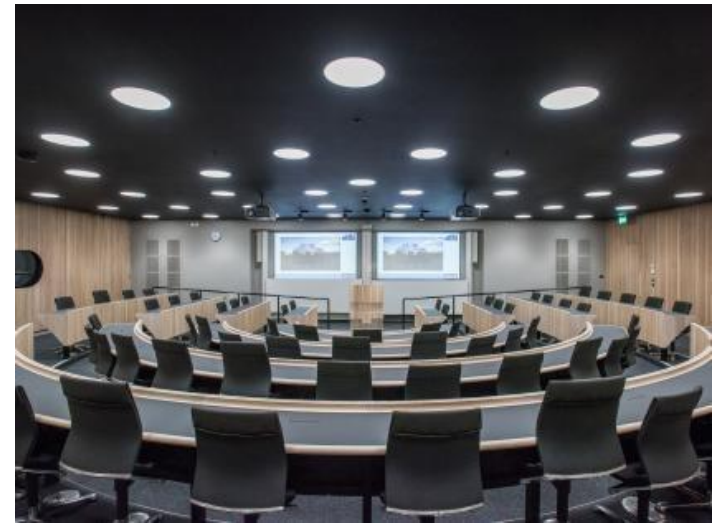

Hình 7. Giảng đường của đại học Blavatnik [7].

\section{- Đại học Cambridge:}

Đại học Cambridge được thành lập năm 1209, với tên đầy đủ là "Viện đại học nghiên cứu công lập liên hợp tại Cambridge", Anh.

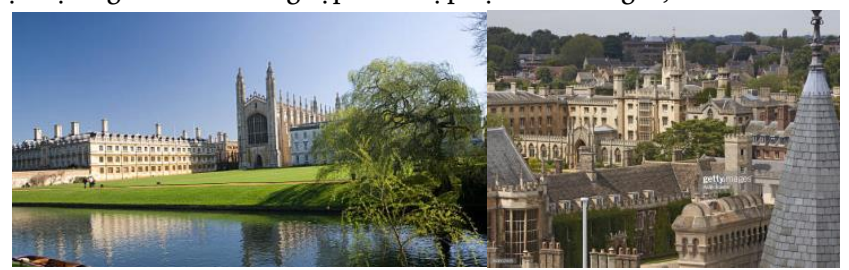

Hình 8. Đại học Cambridge [8].

Cũng giống như ở Oxford, Cambridge có nhiều ngôi trường cổ kính mang phong cách Gothic của kiến trúc thời Trung cổ, những tòa tháp vươn cao, những giáo đường mái vòm và những cánh cửa gỗ được chạm khắc uy nghi. Cambridge rất yên tĩnh, thiên nhiên thanh bình, nhịp sống nhẹ nhàng giúp học viên ở đây có những điều kiện lý tưởng nhất để tập trung vào việc học tập và nghiên cứu.

Khuôn viên của trường rất hiện đại, phục vụ tối đa cho nhu cầu học tập và nghiên cứu của sinh viên. Khu ký túc xá của trường với các phòng được trang bị đầy đủ tiện nghi.

Để phục vụ hơn 18000 sinh viên, trường sở hữu tới 9 bảo tàng nghệ thuật, khoa học và văn hoá. Bên cạnh đó, trường có tới 114 thư viện. Thư viện đại học Cambridge là thư viện nghiên cứu trung tâm, lưu trữ hơn 8 triệu đầu sách.

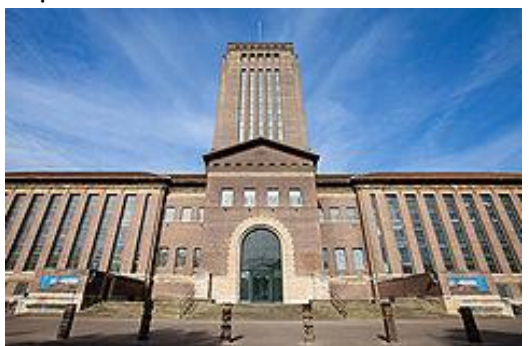

Hình 9. Thư viện đại học Cambridge [9]. 
Thư viện đại học Cambridge, được thiết kế bởi Giles Gilbert Scott, mở cửa năm 1934. Toà nhà có 02 sân sáu tầng song song với một tòa tháp 12 tầng ở trung tâm, và liên kết các cửa sổ theo chiều dọc với các ngăn sách. Phòng đọc chính được chiếu sáng bởi 25 cửa sổ bằng giấy có đầu tròn ở mỗi bên.

\section{4. Đại học Tsukuba (Nhật Bản)}

Đại học Tsukuba nổi tiếng với diện tích khuôn viên trường 258 ha, rộng thứ hai ở Nhật Bản, khoảng 20000 sinh viên, được hình thành với sự quản lý chặt chẽ về mặt quy hoạch từ ban đầu. Trường không xây dựng tường bao ngoài, chỉ sử dụng những không gian cây xanh và hồ nhân tạo để ngăn cách. Mục tiêu cơ bản của trường là xây dựng một không gian mở với hệ thống nghiên cứu, giáo dục linh hoạt cũng như đáp ứng được nhu cầu nhiều mặt của xã hội.

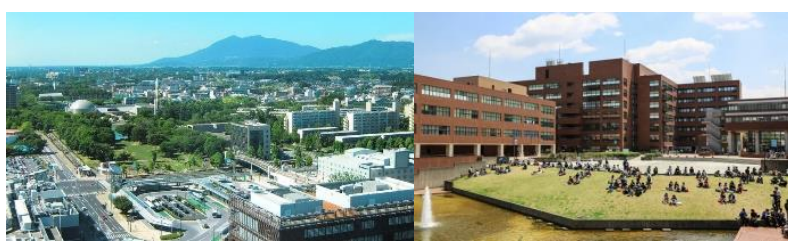

Hình 10. Đại học Tsukuba [10].

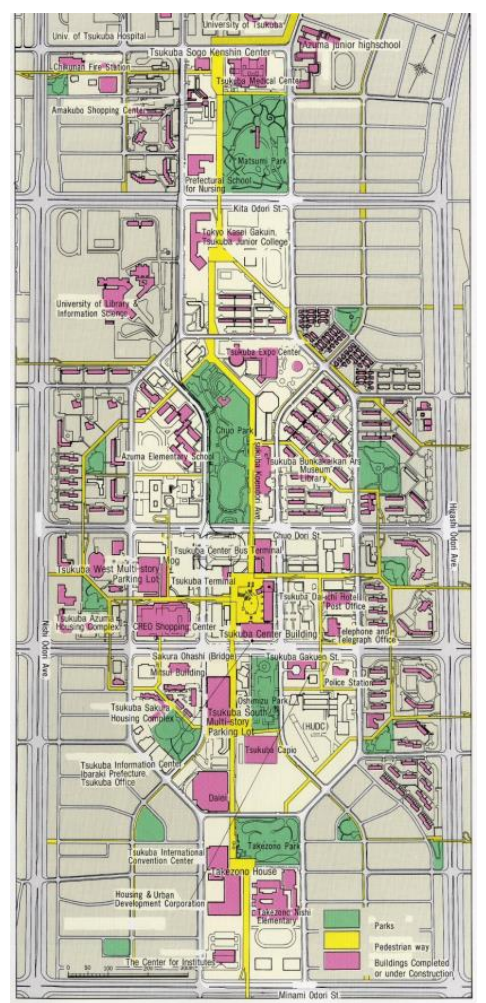

Hình 11. Quy hoạch trung tâm đô thị Tsukuba [11].
Điểm đặc biệt nhất của quy hoạch Tsukuba là đặt trung tâm đô thị ở giữa, đại học Tsukuba ở phía Bắc và các viện nghiên cứu khoa học và kỹ thuật ở phía Nam. Việc tậptrung cácchức năng đô thị, nhà ở, nghiên cứu và giáo dục ở giữa thành phố giúp dễ dàng xác định hạt nhân của thành phố và thống nhất toàn bộ khu vực phát triển phân tán theo hình thuôn dài. Trục chính có một mạng lưới đường dành cho người đi bộ ngăn cách với xe ô tô, 6 quảng trường công cộng và các tiện ích đô thị dọc theo đường đi. Các không gian, dịch vụ công cộng cho cư dân như công viên, trường học, trung tâm mua sắm... được xây dựng dọc theo trục chính và mang đến không gian sống dễ chịu, an toàn.

Các khía cạnh đặc trưng khác của thành phố là tận dụng môi trường tự nhiên phong phú như rừng hiện có và dành một số quỹ đất cho các dự án tương lai như xây dựng hệ thống giao thông mới và các cơ sở văn hóa. Mục đích để phát triển khu ngoại ô xung quanh thành một khu vực đô thị hóa rộng lớn hơn với cốt lõi là khu nghiên cứu và giáo dục.

\section{Một số đô thị đại học tại Việt Nam}

3.1. Đô thị đại học quốc gia Hà Nội

Dự án Đại học quốc giaHà Nội được khởi công vào năm 2003 tại Hòa Lạc (Thạch Thất, Hà Nội) được triển khai trên tổng quỹ đất lên đến 1000ha. Dự án được Chính phủ phê duyệt năm 2003 với mục tiêu chính là xây dựng khu đô thị đại học hiện đại, tiên tiến. Đây cũng sẽ là khu đô thị đại học liên hoàn thống nhất gồm 9 đại học thành viên, 8 viện, 13 trung tâm nghiên cứu, 4 trường THPT chuyên. Quy mô đào tạo dự trữ phát triển cho giai đoạn tầm nhìn đến năm 2050 là 100000 sinh viên.

Dự án được quy hoạch theo mô hình hướng tâm, với các lớp không gian vành đai bao quanh hạt nhân là khu trung tâm. Khu vực trung tâm bao gồm các công trình như trung tâm điều hành, thư viện trung tâm, nhà văn hóa... Vành đai thứ nhất dành cho các khoa trường đại học thành viên. Vành đai ngoài cùng là các cơ sở nghiên cứu, ký túc xá sinh viên, nhà công vụ và các đơn vị hỗ trợ đào tạo. Theo quy hoạch, các công trình ký túc xá sinh viên đáp ứng nhu cầu chỗ ở cho gần 43000 sinh viên.

Theo đánh giá của các chuyên gia, khi đi vào hoạt động, dự án sẽ tác động tích cực đến môi trường - xã hội, hình thành khu vực đô thị đại học với không gian xanh, sáng tạo, mang đến cho sinh viên, giảng viên môi trường học tập tích cực. 


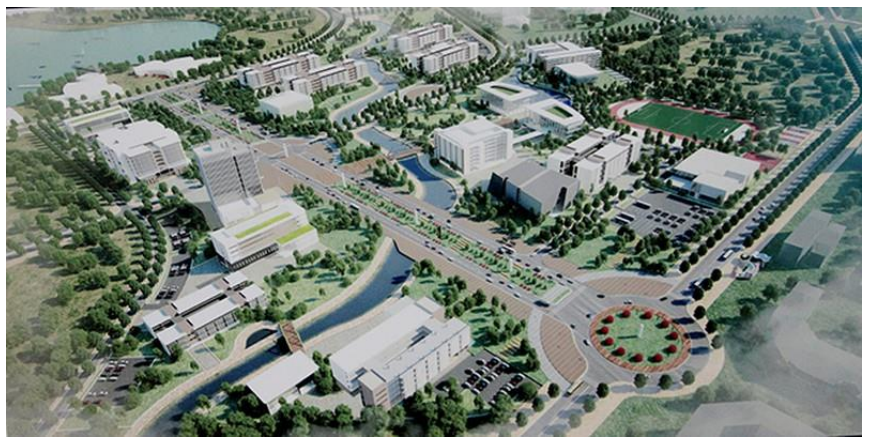

Hình 12.Dự ánđô thịđại học quốc gia Hà Nội [12].

\section{2. Đô thị đại học Đà Nã̃ng}

Dự án đô thị Đại học Đà Nẵng được phê duyệt từ tháng 12/1997 với quy mô phục vụ khoảng 60000 sinh viên tính đến năm 2035; diện tích gần 287 ha thuộc phường Hòa Quý (quận Ngũ Hành Sơn, TP Đà Nẵng) và phường Điện Ngọc (thị xã Điện Bàn, Quảng Nam).Đây là khu chức năng đặc thù, là trung tâm giáo dục đào tạo và nghiên cứu khoa học đa ngành, đa lĩnh vực cấp quốc gia và quốc tế; Gồm các khu cơ bản sau: khu trung tâm, khu học tập và khu nghiên cứu.

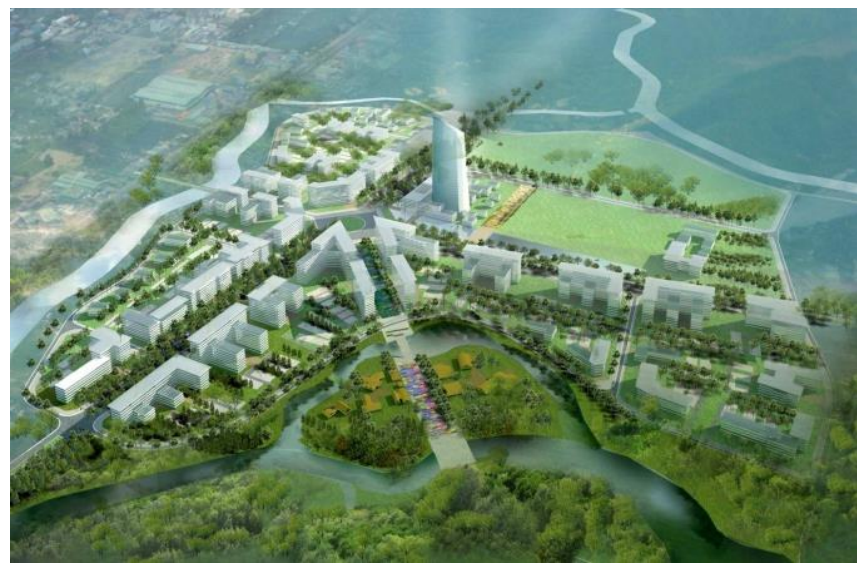

Hình 13.Dự ánđô thịđại học Đà Nẵng [13].

Theo kế hoạch, các công trình khi hoàn thành, dự kiến cuối tháng 6-2022 sẽ đáp ứng nhu cầu đào tạo, nghiên cứu khoa học và làm việc cho các trường $Đ H$ thành viên, đơn vị đào tạo trực thuộc tại khu đô thị ĐH Đà Nẵng.

\section{3. Đô thị đại học quốc gia thành phố Hồ Chí Minh}

Đại học quốc gia thành phố Hồ Chí Minh đang trong lộ trình xây dựng đô thị đại học, tọa lạc tại khu Đông Bắc thành phố, gồm quận 2, quận 9 và quậnThủ Đức. Tổng diện tích khu đất của dự án là 643,7ha, phục vụ quy mô đào tạo đến 50000 sinh viên.

Khu đô thị sau khi hoàn thành sẽ gồm 05 khu chức năng lớn: Khu hành chính - dịch vụ; Khu đào tạo; Khu nghiên cứu - chuyển giao công nghệ (bao gồm khu phần mềm và công viên khoa học); Khu ký túc xá; Khu thể dục thể thao.

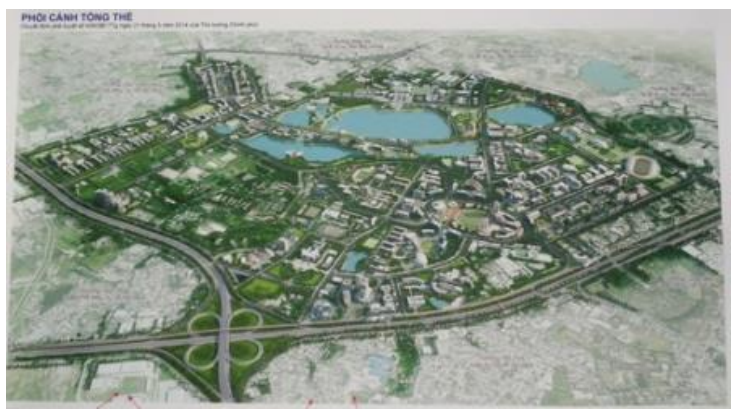

Hình 14.Dự ánđô thịđại học quốc gia Hồ Chí Minh [14].

Một trong những mục tiêu của ĐH Quốc gia TP.HCM trong giai đoạn 2020-2025 là trở thành hạt nhân cho khu đô thị sáng tạo tương tác cao phía đông TP.HCM trên cơ sở trở hình thành khu đô thị xanh, thông minh và thân thiện.

\section{4. Đại học Võ Trường Toản}

Đại học Võ Trường Toản tọa lạc trên Quốc Lộ 1A, Tân Phú Thạnh, Châu Thành $\mathrm{A}$, Hậu Giang, được thiết kế và xây dựng theo lối kiến trúc cổ Châu Âu trên ý tưởng của mô hình "Everything's in one place!"

Cùng với định hướng phát triển trở thành một thành phố Đại học với hệ thống quản lý giáo dục tiên tiến, trường Đại học Võ Trường Toản đầu tư tập trung về cơ sở hạ tầng kỹ thuật nhằm đáp ứng tốt nhất nhu cầu học tập và sinh hoạt của sinh viên. Tại đây, mọi hoạt động dạy và học diễn ra theo một hệ thống thống nhất và đặc biệt là hình thành nên một môi trường học tập và sinh hoạt quy mô, chuyên nghiệp mang nét văn hóa đặc trưng của nhà trường. Trong môi trường học tập năng động và tiện lợi, mỗi sinh viên là một tế bào xây dựng nên một xã hội thu nhỏ lành mạnh, trong sạch, thân thiện và tính kỷ luật cao.

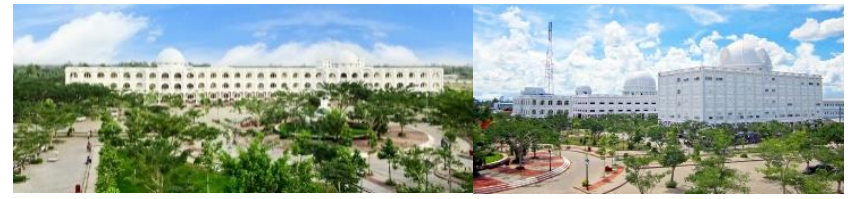

Hình 15. Khu giảng đường lý thuyết và Khu trung tâm thực hành, thí nghiệm y dược - với sắc trắng đặc trưng [14]. 


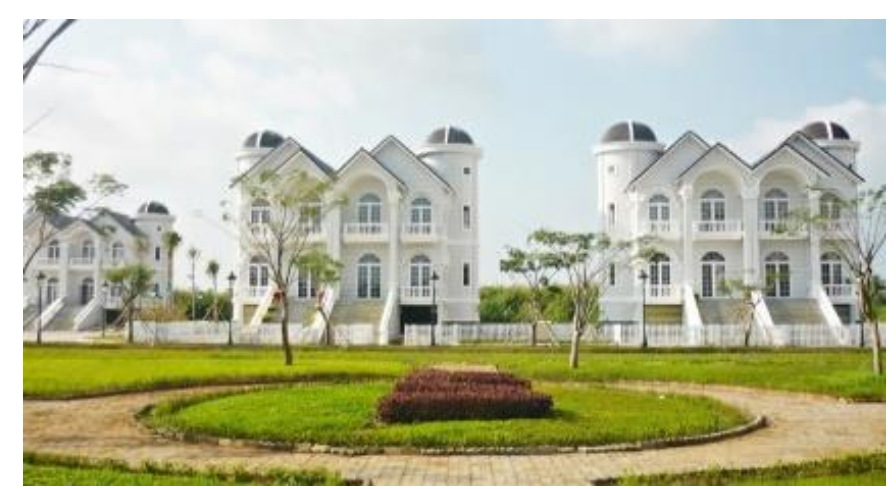

Hình 16. Các tòa của nhà khu biệt thự được thiết kế theo lối kiến trúc cổ Châu Âu [14].

\section{Kết luận}

Mô hình đô thị đại học đã được thực hiện thành công ở nhiều quốc gia phát triển trên thế giới, góp phần trở thành động lực và nền tảng phát triển bền vững riêng của chính đô thị đó. Tại Việt Nam, việc lựa chọn phát triển đô thị đại học có thể là một mô hình rất tốt tạo ra một cách làm mới, phát huy các thế mạnh và sử dụng có hiệu quả các nguồn lực riêng của từng trường đại học thành viên. Tính chất công cộng của những khu trường đại học nổi tiếng là một điểm đáng để chúng ta học tập. Đô thị đại học cần được dung hoà với khu vực xây dựng, trở thành một đô thị với dân cư, xí nghiệp địa phương.

Tuy nhiên, cần áp dụng có chọn lọc các mô hình đô thị đại học từ nước ngoài sao cho phù hợp với con người và điều kiện tự nhiên tại mỗi quốc gia.

Việc lập quy hoạch đô thị đại học cần chính xác về qui mô, độ lớn và vị trí của khu đại học.

Tính chất công cộng, không gian mở của những khu đô thị đại học nổi tiếng là một điểm đáng để chúng ta học tập.

Cần ưu tiên nhu cầu tối đa cho con người, cần chú trọng đến chất lượng của giáo dục chứ không nên chỉ quá chú trọng đến hình thức.

Đô thị đại học cần có điều kiện giao thông, thông tin liên lạc nhanh chóng, thuận lợi. Sinh viên hiện nay, ngoài việc học tập còn triển khai nghiên cứu phục vụ xã hội, bởi vậy phần lớn những khu đô thị đại học cần tập trung xây dựng tại những thành phố lớn, thuận tiện liên lạc.

\section{Tài liệu tham khảo}

[1]. "Take A Harvard Campus Tour on Your Visit to Boston," Forever Lost In Travel, 20/02/2020. https://foreverlostintravel.com/take-a-harvardcampus-tour-on-your-visit-to-boston (truy cập 24/04/2021).
[2]. "87 Widener Library Photos and Premium High Res Pictures," Getty Images. https://www.gettyimages.com/photos/widener-library (truy cập 21/04/2021).

[3]. “Annenberg Hall by the numbers," Harvard Gazette, 17/09/2009. https://news.harvard.edu/gazette/story/2009/09/annenberg-hall/ (truy cập 22/04/2021).

[4]. Vũ Hạnh Quyên, "Đại Học Boston, Hoa Kỳ," Scholarship Planet - Hành Tỉnh Học Bổng. https://scholarshipplanet.info/vi/university/dai-hoc-bostonhoa-ky/ (truy cập 22/01/2021).

[5]. Julia Zorthian, "Oxford Tops Ranking of Best Universities in the World," Time, 22/09/2018. https://time.com/4503991/oxford-best-universitiestimes-higher-education/ (truy cập 25/01/2021).

[6]. Chilaxu, "Thư viện Bodleian lâu đời cổ kính bậc nhất ở Oxford,” iDesign, 26/09/2018. https://idesign.vn/art-and-ads/thu-vien-bodleian-lau-doico-kinh-bac-nhat-o-oxford-268273.html (truy cập 22/02/2021).

[7]. "Blavatnik School of Government," Conference Oxford. https://conferenceoxford.com/venues/conference/blavatnik-school-of-government (truy cập 23/02/2021).

[8]. “28,848 Cambridge University Photos and Premium High Res Pictures," Getty Images. https://www.gettyimages.com/photos/cambridgeuniversity (truy cập 22/04/2021).

[9]. Thư viện Đại học Cambridge - Cambridge University Library,” Wikipedia. https://vi2.wiki/wiki/Cambridge_University_Library （truy cập 25/04/2021).

[10]. “Trường đại học Tsukuba Nhật Bản,” THANGLONGOSC, 26/02/2015. https://thanglongosc.edu.vn/truong-dai-hoc-tsukuba-nhat-ban.html (truy caaph 21/01/2021).

[11]. https://line.17qq.com/articles/bdfeephdz.html. (truy cập 25/04/2021).

[12]. Nhật Thanh, "Xây dựng Đại học Quốc gia Hà Nội trở thành đô thị đại học tại Hòa Lạc," Báo điện tử Pháp luật Việt Nam, 10/07/2017. https://baophapluat.vn/xay-dung-dai-hoc-quoc-gia-ha-noi-tro-thanh-dothi-dai-hoc-tai-hoa-lac-post259454.html (truy cập 21/01/2021).

[13]. “Tái khởi động dự án đô thị làng đại học Đà Nẵng,” 03/04/2019. https://linkhousemientrung.com.vn/tin-tuc/tai-khoi-dong-du-an-khu-dothi-lang-dai-hoc-da-nang-gan-9-000-ty-dong.html (truy cập 01/08/2021).

[14]. “Thông tin các cuộc thi thiết kế quy hoạch," 12/11/2018. https://qhkt.hochiminhcity.gov.vn/thong-tin-cac-cuoc-thi-thiet-ke-quyhoach.html (truy cập 01/05/2021).

[15]. Đại học Võ Trường Toản. http://www.vttu.edu.vn/ (truy cập 21/04/2021). 